\title{
The Burnout among Multinational Nurses in Saudi Arabia
}

\author{
Maram Hani Batayneh"1,2, Shaukat Ali3 ${ }^{3}$, Abdulqadir J. Nashwan",5 (i) \\ ${ }^{1}$ Alinma Medical Services Group, Riyadh, Saudi Arabia \\ ${ }^{2}$ University of Liverpool, Liverpool, UK \\ ${ }^{3}$ University of Wolverhampton Business School, Wolverhampton, UK \\ ${ }^{4}$ Hamad Medical Corporation, Doha, Qatar \\ ${ }^{5}$ University of Calgary in Qatar, Doha, Qatar \\ Email: marambataineh@yahoo.com, shaukat.ali@wlv.ac.uk, anashwan@hamad.qa
}

How to cite this paper: Batayneh, M.H., Ali, S. and Nashwan, A.J. (2019) The Burnout among Multinational Nurses in Saudi Arabia. Open Journal of Nursing, 9, 603619.

https://doi.org/10.4236/ojn.2019.97049

Received: May 27, 2019

Accepted: July 5, 2019

Published: July 8, 2019

Copyright () 2019 by author(s) and Scientific Research Publishing Inc. This work is licensed under the Creative Commons Attribution International License (CC BY 4.0).

http://creativecommons.org/licenses/by/4.0/

\begin{abstract}
Aim: To examine the relationship between workplace stress, job satisfaction, intention-to-leave and the development of burnout among multinational nurses in Saudi Arabia (SA). Background: Burnout among healthcare workers is a critical issue that has negative impacts on staff well-being, turnover rate, patients' care quality, and the overall organizations' performance. Moreover, Saudi Arabia's reliance on overseas nurses forms a unique working environment, where most nurses are working outside their home countries. The study was conducted at KFMC in Riyadh; a $\mathrm{MOH}$ affiliated tertiary care hospital with a 3000 multinational nursing workforce. Methods: A correlational, cross-sectional study was conducted over the period 1 August to 30 December 2016 to identify demographics, causes of job stress, burnout, job satisfaction, and nurses' intention-to-leave. Two hundred and twenty-four nurses completed the survey. Results: 313 responses were collected (RR: 10.5\%); of the total responses, 224 met the inclusion criteria. Workplace stress and nurses' intention-to-leave have a positive correlation with the development of burnout symptoms. While job satisfaction levels had a negative correlation with the development of burnout symptoms. Overall, nurses' demographics had no significant effect on the development of burnout. Conclusion: Multinational nurses in Saudi Arabia suffer from work-related stress and burnout that can translate into high turnover, which in turn can be detrimental to the health organizations in the country. Implications for Nursing Management: Vigilant strategies and interventions are required to improve the nurses working environment.
\end{abstract}

\section{Keywords}

Burnout, Nursing, Saudi Arabia, Workplace Stress 


\section{Introduction}

Research shows that healthcare professionals are at high risk of developing burnout as a result of a stressful working environment, extensive responsibilities and heavy workloads in healthcare sectors [1] [2] [3]. The prolonged exposure to work stress is a potential hazard in healthcare organizations, leading to burnout [4]. In 2007, Turton alluded that nurses suffer from higher stress levels compared with other healthcare providers due to the nature of their working environment, one characterized by a high level of emotional strains which stem from their daily exposure to sick and dying patients [5].

Healthcare organizations are highly dynamic systems characterized by continuous change. The ongoing increase in the demand for healthcare services, coupled with the limited resources available to meet these demands imposes tremendous pressures on health organizations [6]. The recent global healthcare systems reform movement led to fundamental changes in the structure of these systems [7] [8]. Thus, several studies showed that organizational transformation and change increases workplace stress [9] [10] [11].

Over the past few decades, the burnout phenomenon has attracted many researchers to investigate its negative effects on employees, patients and health organizations [2] [12] [13] [14]. The term burnout was first coined by the American psychologist Herbert Freudenberger in 1974 [3]. Herbert used the term to describe the severe exhaustion experienced by helping professions such as policemen, doctors, and nurses. Today, the term has expanded to include all professionals who suffer from an extreme stress state. Burnout is defined as "a state of emotional, mental, and physical exhaustion caused by excessive and prolonged stress" [15]. The burnout syndrome consists of three major dimensions: emotional exhaustion (EE), depersonalization (DP), and reduced personal accomplishment (PA) [15]. Staff who suffer from burnout usually feel disengaged, apathetic, and, demotivated [16], which leads to recurrent absenteeism from the workplace [3]. Burnout may have serious negative effects on patients' care quality and outcomes [16], which is serious and can never be underestimated by hospital leadership.

In healthcare organizations, nurses form the largest workforce among other healthcare providers [17]. Therefore, it is imperative to identify the main factors that contribute to the development of burnout in nursing [12] and to gauge its effect on nurses, patients, and health organizations. Numerous studies were conducted to explore the development of burnout among nurses [1] [14] [18]. However, only a few studies have been conducted in Saudi Arabia to investigate burnout syndrome among nurses. A study by Al-Turki et al. showed that a majority of multinational nurses who worked in a tertiary care hospital in Saudi Arabia were in a state of burnout with high-frequency EE and DP. Nonetheless, there were no preceding studies that have been conducted to explore the relationship between the development of burnout and workplace stress, job satisfaction and intention-to-leave among the multinational nurses Saudi Arabian hospitals 
[13].

In the Kingdom of Saudi Arabia (KSA), the healthcare system went through a substantial transformation in terms of healthcare structure, size, scope, coverage, technology as well as the inevitable impact of wider globalization forces [19]. Nonetheless, to date KSA still relies heavily on an expatriate nursing workforce. According to Al-Turki et al. (2010), the expatriate nurses form over $70 \%$ of the total nursing workforce in KSA [12]. Furthermore, Almalki and colleagues pointed out that the turnover rate among nurses is very high in KSA [20].

\section{Aims of the Study}

The aims of the study were: 1) To explore the effect of workplace stress on the development of burnout among multinational nurses in SA. 2) To assess the effect of job satisfaction level on the development of burnout syndrome among multinational nurses at SA hospitals. 3) To identify the relationship between burnout and intention-to-leave work among multinational nurses who work in SA and 4) To identify the demographic features (i.e. age, gender, and working experience) impacting the development of burnout among multinational nurses who work in SA.

\section{Methods}

\subsection{Research Design}

A non-experimental, cross-sectional and correlational study was conducted as conducted over the period 1 August to 30 December 2016 to examine the strength of the relationships, or the association, between variables that occur naturally, rather than direct cause-effect relationships. Several existing models, frameworks and inventories are utilized for primary data.

The significance of this approach in this study stems from the fact that, as the literature shows, burnout is a global phenomenon among nurses, correlating with other work-related phenomena such as job stress, job satisfaction, and intention-to-leave work. Using a quantitative research approach enables the researchers to measure the relationship between study variables and to examine their prevalence, frequency and pattern. In doing so, this will add to the global body of knowledge related to burnout. Due to the scarcity of research that investigated the burnout relationship with the aforementioned variables in Saudi Arabia, our empirical data will offer a robust explanation in understanding this phenomenon, helping the Saudi healthcare administrators to generate appropriate strategies to mitigate burnout prevalence and its subsequent effects on healthcare organizations in the Kingdom.

\subsection{Burnout Model}

Primary data collection was undertaken using the Maslach Burnout Inventory (MBI), developed by Maslach and Jackson in 1981 [15]. The MBI is one of the most widely used research instrument for assessing burnout [21]. MBI measures 
three dimensions [emotional exhaustion (EE) which measures individual feelings of being emotionally exhausted and depleted by one's work; depersonalization (DP) which captures the development of negative, cynical attitudes and feelings towards clients and personal accomplishment (PA), which assess the individual sense of ineffectiveness, especially with job performance [15] [22]. The scale validity and reliability were established by Maslach \& Jackson (1981) and was confirmed in several studies [23] [24] [25]. In 2009, Poghosyan and colleagues conducted a confirmatory and exploratory factor analysis study to examine the MBI subscale performance validity and reliability in different samples of nurses in eight different countries (U.S., Canada, the U.K., Germany, New Zealand, Russia, Armenia, and Japan). The study included 54,738 nurses in 646 hospitals. The results confirmed that the MBI subscales were significantly correlated and equally valid and reliable measures of burnout. The significance of this extremely large study is that it provides confirmatory evidence of confidence in the MBI instrument to measure the correlates of nurse burnout globally [21].

\subsection{Job Stress Model}

The Job Stress Model was developed in 1981 by Gray-Toft and Anderson to measure stress among nurses [26]. The section adopted for this research instrument was from the Nurse Stress Scale (NSS), which is a multidimensional construct composed of 34 items addressing nurses' sources of stress in the workplace. The scale is the best known and most widely used in nursing [27]. The questionnaire provides a seven-point Likert scale measuring stress experience frequency and the total level of stress. In 2000, French et al. developed an expanded instrument (ENSS) to gauge precise measurement for the actual situations experienced by nurses. The scale is constructed of nine subscales: death and dying, conflict with physicians, inadequate preparation, problems with peers, problems with supervisors, workload, and uncertainty concerning treatment, patients, and their families, and discrimination [27]. The model validity and reliability was established by French et al., 2000 and was confirmed in several studies [28] [29] [30] [31]. Given its proven robustness this study uses the ENSS instrument.

\subsection{Job Satisfaction Model}

Price and Mueller (1981) developed a framework model to gauge intention-to-stay, turnover and job satisfaction in nursing [32]. The model consists of nine exogenous factors namely routinization, centralization, instrumental communication, integration, pay, distributive justice, promotional opportunity, role overload, and professionalism. Since the job satisfaction model is embedded in Price and Mueller original model, in 1993 the model was revised into a job satisfaction framework to include motivation as a significant factor contributing to job satisfaction. The Price-Mueller Model of job satisfaction examines the impact of environmental (opportunity), job characteristics (autonomy, role ambiguity, role conflict, role overload, distributive justice, supervisory support, internal labor 
market, task significance, integration, pay and routinisation) and personality variables (work motivation, positive affectivity, and negative affectivity) to provide a comprehensive framework for analyzing and understanding employees' job satisfaction [33]. As intention-to-leave is a key determinant of this research, the Price-Mueller Model offers much congruence, with its validity and reliability strengthened not just by Price and Mueller (1981) but confirmed by several researchers [33] [34] [35] [36].

\subsection{Intention-to-Leave Model}

In order to gauge nurses' intention-to-leave the questionnaire will include the following question "Are you currently considering leaving the Hospital?" by choosing one of the three options, yes, no or undecided. This question was modified from the original question used by Sabanciogullari \& Dogan (2015) "Are you currently considering leaving the profession?" [37]. This question has been reported as a reasonably valid measure of intention-to-leave the profession in a proceeding study [38].

\subsection{Sampling Design and Study Location}

The sampling pattern was a critical part of this study, due to its substantial effect on the research's findings. In this study, the authors adopt a simple random sampling technique where all members of the population had equal chances to be part of the study. The target population was all registered nurses who completed one year or more at King Fahad Medical City, Riyadh-a MOH affiliated tertiary care hospital with a 3000 multinational nursing workforce.

The estimated sample was calculated using power analysis with the total population of approximately 3000 nurses working in KFMC with $90 \% \mathrm{CI}$; so the minimum sample size was 249 .

\subsection{Data Collection Techniques}

The primary data was collected through a web-based questionnaire designed on Survey Monkey ${ }^{\circledR}$. The tool allows users to download the data directly into an analysis program avoiding transcription errors. The web link was forwarded to the participants through their email address. The survey was available for the participants for two weeks. To obtain a higher response rate, a reminder email was sent to the participants. Three hundred and twelve nurses completed the questionnaire.

\subsection{Pilot Study}

In order to assess the adequacy and the feasibility of the intended research, a pilot study was conducted for the survey with a group of five multinational nurses who work at another hospital in Saudi Arabia. The participants reported that the questionnaire was clear but somewhat long. In light of this the authors modified the original questionnaire and reduced the items from 88 to 72 . 


\section{Data Analysis Strategies}

The collected data was entered into a database and analyzed using the Statistical Package for the Social Sciences (SPSS) to calculate means, variance and correlation factors. This approach allowed the researchers to carry out comparisons between study variables and measure their prevalence in relation to key variables.

\section{Psychometric Measures of the Instrument}

The validity refers to the extent to which an instrument measures what it supposed to measure. The validity of the instrument was examined by a correlation coefficient measure. Correlation coefficient test (Pearson's $r$ ) was used to determine the strength and the direction of the linear relationship between the variables [39]. Pearson's $r$ measures the linear correlation between two variables and score between $(-1$ to +1$)$. The positive correlations indicate appositive relationship between two variables, while negative correlations indicate an inverse relationship between the variables analyzed. The reliability of the instrument was examined to measure the stability and the internal consistency of the data collected to answer the research questions. The significance of this step is that statistical reliability indicates that the study may be repeated on a different population sample using the same measures. Cronbach's alpha measure was used to examine the internal consistency among the instrument's items [39]. Cronbach Alpha has been found to be between 0.84 and 0.97 , showing high reliability.

\section{Ethical Considerations}

Ethical approval from King Fahad Medical City Academic \& Training Affairs Research \& Scientific Publication Center was secured as well as authors' host institutions.

\section{Results}

Participants were asked to provide data related their age, gender, marital status, nationality, educational level, years of experience, work location, current position and working hours. Results have revealed that the respondents' age varied from 20 to 60 years old. $34.4 \%(\mathrm{n}=77)$ were between 20 to $30,33 \%(\mathrm{n}=74)$ were between 31 to $40,26.3 \%(n=59)$ between 41 to 50 , and those between 51 to 60 only represented $6.3 \%(n=14)$. Analysis of the gender shows that $8.9 \%(n=$ $20)$ of the respondents were Males and $91.1 \%$ where Females $(n=204)$. The data also showed that the majority of the respondents $61.2 \%(n=137)$ were married whereas the remaining reported to be single $(38.2 \%, \mathrm{n}=77)$ (see Table 1 ).

Table 2 shows that there is an inverse correlation (negative) between Job satisfaction and symptoms of burnout. This indicates that the higher the job satisfaction levels, the more the symptoms of burnout decline ( $\mathrm{p}$-value of 0.01 ).

Table 3 shows the results related to nurses' intention-to-leave their current employer. Results revealed that $18.8 \%(n=42)$ had intentions to leave while, 
Table 1. Distribution of study sample according to demographic characteristics.

\begin{tabular}{|c|c|c|}
\hline Items & Frequency & Percentage (\%) \\
\hline \multicolumn{3}{|c|}{ Age } \\
\hline 20 - 30 years & 77 & 34.4 \\
\hline 31 - 40 years & 74 & 33.0 \\
\hline $41-50$ years & 59 & 26.3 \\
\hline 51 - 60 years & 14 & 6.3 \\
\hline \multicolumn{3}{|c|}{ Gender } \\
\hline Male & 20 & 8.9 \\
\hline Female & 204 & 91.1 \\
\hline \multicolumn{3}{|c|}{ Marital Status } \\
\hline Single & 87 & 38.8 \\
\hline Married & 137 & 61.2 \\
\hline \multicolumn{3}{|c|}{ Nationality } \\
\hline American & 1 & 0.4 \\
\hline Asian & 2 & 0.9 \\
\hline Australian & 1 & 0.4 \\
\hline Pilipino & 151 & 67.4 \\
\hline Indian & 44 & 19.6 \\
\hline Jordanian & 8 & 3.6 \\
\hline Malaysian & 2 & 0.9 \\
\hline Pakistani & 3 & 1.3 \\
\hline Saudi & 5 & 2.2 \\
\hline South African & 5 & 2.2 \\
\hline Missing & 2 & 0.9 \\
\hline \multicolumn{3}{|c|}{ Qualification } \\
\hline Diploma & 33 & 14.7 \\
\hline Bachelors & 174 & 77.7 \\
\hline Master or Doctorate & 16 & 7.1 \\
\hline Missing & 1 & 0.4 \\
\hline \multicolumn{3}{|c|}{ Experience in practicing nursing } \\
\hline $1-10$ Years & 110 & 49.1 \\
\hline $11-20$ Years & 74 & 33.0 \\
\hline $21-30$ Years & 32 & 14.3 \\
\hline More than 30 Years & 8 & 3.6 \\
\hline \multicolumn{3}{|c|}{ Experience in working in the hospital } \\
\hline $0-10$ Years & 174 & 77.7 \\
\hline $11-20$ Years & 47 & 21.0 \\
\hline $21-30$ Years & 3 & 1.3 \\
\hline
\end{tabular}




\section{Continued}

\begin{tabular}{ccc}
\hline & Primary area of work & \\
Medical & 23 & 10.3 \\
Surgical & 21 & 9.4 \\
Emergency & 9 & 4.0 \\
Critical Care & 33 & 14.7 \\
Pediatric Unit & 31 & 13.8 \\
Obstetric & 10 & 4.5 \\
Others & 97 & 43.3 \\
& Current position title & \\
Staff Nurse & 165 & 73.7 \\
Head Nurse & 17 & 7.6 \\
Charge Nurse & 27 & 12.1 \\
Others & 15 & 6.7 \\
& Shift hours & 65.6 \\
8 Hours & 147 & 34.4 \\
\hline 2 Hours & 77 & \\
\hline
\end{tabular}

Table 2. Pearson correlation between job satisfaction and symptoms of burnout.

\begin{tabular}{cc}
\hline Description & Rang of mean \\
\hline Strongly agree & $3.26-4.00$ \\
Agree & $2.51-3.25$ \\
Disagree & $1.76-2.50$ \\
Strongly disagree & $1.00-1.75$
\end{tabular}

Table 3. Distribution of study sample according to intention-to-leave current work.

\begin{tabular}{ccc}
\hline Answer & Frequency & Percentage \\
\hline No & 93 & 41.5 \\
Undecided & 89 & 39.7 \\
Yes & 42 & 18.8 \\
Total & $\mathbf{2 2 4}$ & $\mathbf{1 0 0 . 0}$ \\
\hline
\end{tabular}

$39.7 \%(n=89)$ had not decided yet. More specifically there was a direct positive correlation between Intention-to-leave current work and symptoms of burnout ( $\mathrm{p}$-value of 0.01 ). This indicates that the development of burnout symptoms is a predictor of turnover intention.

The results show that there is a direct positive correlation between external causes of stress and the development of burnout symptoms (p-value 0.01). It was also found that there is a direct positive correlation between internal causes of stress and symptoms of burnout (p-value 0.01). Furthermore, our analysis re- 
vealed that there is a direct positive correlation between causes of job stress in general and symptoms of burnout (p-value 0.01) (see Table 4).

\section{Demographic Features Impact on the Development of Burnout}

As shown in Table 5, there were no statistically significant differences in symptoms of burnout with differences in age, gender, marital status, staff qualifications, years of experience in nursing, years of experience in the current hospital, the primary area of work, or position. On the other hand, there were statistically significant differences between those that worked 8 or 12 hours shifts ( $p$-value 0.001). Those working 12 hours shifts had a greater preponderance for burnout symptoms.

Table 4. Pearson correlation between causes of job stress and symptoms of burnout.

\begin{tabular}{cccc} 
The dimensions & $\begin{array}{c}\text { The correlation } \\
\text { coefficient }\end{array}$ & $\begin{array}{c}\text { Sig. } \\
\text { (2-tailed) }\end{array}$ & Describe the relationship \\
\hline External causes of stress & 0.5157 & 0.01 & Positive relationship \\
Internal causes of stress & 0.5016 & 0.01 & Positive relationship \\
Causes of Job Stress & 0.5302 & 0.01 & Positive relationship \\
\hline
\end{tabular}

Table 5. One way analysis of variance (F-test) for the difference in symptoms of burnout according to the differences in Age.

\begin{tabular}{|c|c|c|c|c|c|c|}
\hline variables & Source & $\begin{array}{l}\text { Sum of } \\
\text { Squares }\end{array}$ & $\mathrm{df}$ & $\begin{array}{l}\text { Mean } \\
\text { Square }\end{array}$ & $\mathrm{F}$ & $\mathrm{P}$-value \\
\hline \multirow{2}{*}{ Age } & Between Groups & 1.35 & 3 & 0.45 & \multirow{2}{*}{1.32} & \multirow{2}{*}{$\begin{array}{l}0.270 \\
\text { (N. S.) }\end{array}$} \\
\hline & Within Groups & 75.44 & 220 & 0.34 & & \\
\hline \multirow{2}{*}{ Gender } & Male & 20 & 1.94 & 0.60 & \multirow{2}{*}{1.41} & \multirow{2}{*}{$\begin{array}{l}0.160 \\
\text { (N. S.) }\end{array}$} \\
\hline & Female & 204 & 1.75 & 0.58 & & \\
\hline \multirow{2}{*}{ Marital Status } & Single & 87 & 1.81 & 0.64 & \multirow{2}{*}{0.84} & \multirow{2}{*}{$\begin{array}{l}0.405 \\
\text { (N. S.) }\end{array}$} \\
\hline & Married & 137 & 1.74 & 0.55 & & \\
\hline \multirow{2}{*}{$\begin{array}{c}\text { Nursing } \\
\text { qualification }\end{array}$} & Between Groups & 0.15 & 2 & 0.08 & \multirow{2}{*}{0.22} & \multirow{2}{*}{$\begin{array}{l}0.804 \\
\text { (N. S.) }\end{array}$} \\
\hline & Within Groups & 76.59 & 220 & 0.35 & & \\
\hline \multirow{2}{*}{$\begin{array}{l}\text { Years of experience } \\
\text { in nursing }\end{array}$} & Between Groups & 0.93 & 2 & 0.47 & \multirow{2}{*}{1.36} & \multirow{2}{*}{$\begin{array}{l}0.260 \\
\text { (N. S.) }\end{array}$} \\
\hline & Within Groups & 75.87 & 221 & 0.34 & & \\
\hline \multirow{2}{*}{$\begin{array}{c}\text { Years of experience } \\
\text { in the current } \\
\text { hospital }\end{array}$} & 0 - 10 Years & 174 & 1.77 & 0.61 & \multirow{2}{*}{0.02} & \multirow{2}{*}{$\begin{array}{c}0.983 \\
(\text { N. S.) }\end{array}$} \\
\hline & More than 10 Years & 50 & 1.77 & 0.51 & & \\
\hline \multirow{2}{*}{ Work location } & Between Groups & 3.04 & 6 & 0.51 & \multirow{2}{*}{1.49} & \multirow{2}{*}{$\begin{array}{l}0.182 \\
\text { (N. S.) }\end{array}$} \\
\hline & Within Groups & 73.75 & 217 & 0.34 & & \\
\hline \multirow{2}{*}{ Position } & Between Groups & 0.25 & 3 & 0.08 & \multirow{2}{*}{0.24} & \multirow{2}{*}{$\begin{array}{l}0.870 \\
\text { (N. S.) }\end{array}$} \\
\hline & Within Groups & 76.55 & 220 & 0.35 & & \\
\hline \multirow{2}{*}{ Shift duration } & 8 Hours & 147 & 1.67 & 0.58 & \multirow{2}{*}{3.36} & \multirow{2}{*}{$\begin{array}{l}0.001 \\
(0.01)\end{array}$} \\
\hline & 12 Hours & 77 & 1.94 & 0.55 & & \\
\hline
\end{tabular}




\section{Discussion}

In this study, age groups were chosen in accordance with the $\mathrm{MOH}$ and hospital hiring guidelines where nurses are expected to be above 20 years old and not more than 60 as per the Saudi Labor \& Workmen Law [40]. The majority of the respondents who fully completed the questionnaire were female $91.1 \%$, from Philippines 67.4\%, 205 from India, married 61.2\%, younger than 40 years of age $67 \%$ and with bachelor degree $77.7 \%$. More than two-thirds of the participants were Staff Nurses (73.7\%) and 65.6\% of them are working in an 8-hour shift. Only $2.2 \%(n=5)$ were Saudi nationals. These results are not surprising and may represent the real ratios of staff in such hospitals. According to Lamadah \& Sayed (2014) the majority of nurses in Saudi Arabia are from the Far-East, with Saudi national nurses forming about $37.2 \%$ of the workforce [41]. Most nurses had less than 10 years of experience. Notably, almost half of the nurses had been with their current hospital for less than 10 years, which reflects the transient nature among the multinational nurses. Given that expatriate nurses form the majority of the healthcare workforce, the ongoing expansion in the healthcare services as well as, the low enrolment among young Saudis into the profession; highlights the pressing need for retention strategies. Retaining foreign nurses for a longer period will not only sustain the quality of the care but, also assist new nursing graduates to be more socialized into the profession. In turn, this will help the Saudi healthcare system to establish a strong foundation in the profession.

Contrary to the findings of two studies which showed that nurses demographic characteristics and work location correlated with stress and burnout, the findings from this study showed that the nurses' demographic features have no significant effect on the development of burnout. In addition the nurses' years of experience, current experience, work location and position were also found to have no significant effect on burnout development. Nonetheless, it was found that shift duration ( 8 hours) has a significant impact on burnout development (p-value 0.001). This result may be attributed to the work/off the pattern that allows the nurses who work for 12 hours shift to have more off days compared with those who work on 8 hours regimen [12] [42]. Al-Makhaita and colleagues confirmed that shift work is a strong predictor of stress [42].

The relationship between job stress and burnout is well established in the literature. These two variables have a strong positive correlation. In this study nurses' main external sources of stress stems from situations that are related to conflict with physicians, workload and shortages. Around half of the respondents $48.7 \%$ reported that physicians' absences during medical emergencies is an extremely stressful situation to be in. Another two studies found that workload is highly associated with work-related stress [14] [42]. Laranjeira (2011) affirmed that emergency situations were one of the top three stressors for Portuguese nurses [43]. On the other hand, $20.5 \%$ of the nurses reported that "Performing procedures that patients experience as painful" is the least stressful condition. 
The significance of this finding is that it may indicate a lack of care and empathetic aspects in the nursing care provided to the patients. According to Maslach \& Jackson (1981) nurses who suffer from burnout develop negative attitudes and feelings towards patients. The data analysis depicts a positive correlation between external causes of stress and symptoms of burnout (P-value 0.01 ) with a total mean score of $3.53(\mathrm{SD}=0.87)$ [15]. Same results were obtained in China [44].

In the same context of work-stress, nurses' internal stress was driven by workload and uncertainty related to treatment. $26.3 \%$ believed that making decisions under pressure is "always" stressful and, $17.4 \%$ found that "often" stressful. Interestingly the nurses reported that fear of making a mistake and making decisions when physicians are not available are also extremely stressful situations. It is imperative to point out here that participants' responses imply great stress encountered with situations that had to do with decision making. Moreover, it was reported that physicians are also contributing to nurses' internal stress. Interestingly when it comes to least stressing situations, nurses indicated that working with other nurses-whether same gender or not-is never stressful. Results showed that there is a positive correlation between internal causes of stress and symptoms of burnout (P-value 0.01 ) with a total mean score of 3.07 $(\mathrm{SD}=0.89)$.

Job satisfaction is essential at any workplace, therefore in this study nurses' job satisfaction level was measured and analyzed. According to the results almost one-third of the participants are very satisfied with their work accomplishment with an average mean score of 3.29 ( $S D=0.61)$. In 2014, Atefi et al. confirmed that nurses' job satisfaction is highly correlated with their sense of helping others who are in need [45]. This result was previously confirmed by other researchers that nurses' sense of accomplishment has a positive effect on their job satisfaction level. Conversely the respondents' least satisfying aspects of the job were related to benefits and job security with mean scores of $2.69(\mathrm{SD}=0.84)$ and 2.83 $(\mathrm{SD}=0.78)$ respectively [46]. These results are similar to [47] [48] who reported that job security and payment have a directcorrelation with job satisfaction level. Finally, the data indicates that job satisfaction has a negative correlation with burnout symptoms (P-value 0.01 ), with a total mean score of $3.00(\mathrm{SD}=0.54)$.

The main aim of this study was to explore the relationship between workplace stress and job satisfaction level on the prevalence of burnout. The results related to burnout syndrome showed that workload, exhaustion and fatigue are the main sources for nurses' burnout with average mean scores of $2.41(\mathrm{SD}=1.01)$, $2.29(\mathrm{SD}=0.97)$ and $2.05(\mathrm{SD}=0.98)$ respectively. Same results were obtained in China, India, Germany and Saudi Arabia by [13] [17] [49] [50] [51] respectively. The direct correlation between work-related stress and burnout is clearly exhibited in this study results. It was noticed that workload is a predictor of stress and burnout development. Same results were obtained by Vargas et al. [52]. Nonetheless, when it comes to nurses' perceptions related to their care approach the majority of the nurses $87.5 \%(n=196)$ believed that they did not develop any 
negative feelings toward their patients. These results indicate that the nurses suffered from EE that highly associated with work stress and workload, with a total mean score of 1.77 ( $\mathrm{SD}=0.59)$. On the other hand, nurses reported low DP symptoms that may be due to their sense of accomplishment.

The analysis related to nurses' intention to leave their current employer showed that $18.8 \%(n=42)$ have intentions to leave and $39.7 \%(n=89)$ had not decided. The authors attributed this result to the fact that the nurses will not consider leaving their current job unless they have another opportunity therefore, more than one-third of the respondents stated that they had not decided. This result is consistent with the findings from Takase who established that an employee passes through various stages before actually leaving his workplace. According to Takase planning to leave is a multi-stage process that starts with a mental state (intention) and ends with action (leaving) [53]. In this study the correlation between nurses' intention to leave and burnout symptoms is significant and positive, consistent with [14] in that burnout development plays a vital role in the process leading nurses to leave their job.

Overall, the results showed that there is a direct correlation between job stress, job satisfaction, burnout, and intention to leave. This result was consistent with [54] on job stress, burnout and turnover. In addition it was observed that job stress is a strong predictor of nurses' burnout, while job satisfaction decreases the prevalence of burnout symptoms.

In conclusion, focusing on a population of the largely expatriate workforce, this is the first paper to validate generalization of previous findings of burnout in Saudi Arabia showing relationships between job-related stress, job satisfaction, intention-to-leave, turnover, and burnout.

\section{Limitations of the Study}

The first limitation was lacking time to reach more respondents. The second limitation was the methodology; a mixed methodology incorporating a qualitative method (i.e. focus group or semi-structured interviews) would have given deeper insights into the lived experiences of nurses. Although quantitative research provides a scientific approach to understanding the cause and effect of the variables, this design deprived the study of understanding the behaviors related to the burnout phenomenon. Furthermore, the respondents' nationalities were mainly from the Far East and the Middle East countries, thus the exhibition of burnout symptoms may have been different if there was a greater diversity in the nationalities (i.e. Westerners). However, since nurses from western countries form a minority of the multinational workforce in Saudi Arabia; it would be difficult to capture this group in a survey study. Finally, as a single site study, generalizability is limited in applicability to this region.

\section{Conclusion}

The significant conclusions from this research are that multinational nurses in 
Saudi Arabia suffer from burnout due to workload and work-related stress. Some clear outcomes showed that job satisfaction was inversely correlated with burnout symptoms; there was a link to symptoms of burnout and intentions to leave; and there was a link to symptoms of burnout and number of shift hours. More generally, the results showed that staff burnout stemmed from a combination of workload, exhaustion and stress. In light of the key findings, in the next section, we note some of the implications and recommendation for nursing managers.

\section{Implications and Recommendation for Nursing Management}

Causes of stress have numerous causal factors and whilst our research was correlational themed, it is clear that the nursing management can take several tangible measures to mitigate stress and thereby mitigate burnout.

1) Job contracts need to be designed to ensure job security

2) There is a need to promote workplace stability by introducing teamwork and team-building activities to boost confidence and enhance independent decision-making abilities.

3) Ensure 8-hour shifts patterns are the norm and only on an exceptional case such long hours be allowed.

4) Ensure there is constant physician presence or at least availability, to provide a level of comfort to nursing staff.

\section{Acknowledgements}

A special appreciation is also extended to King Fahad Medical City for providing me the opportunity to conduct this research. Further, I wish to acknowledge and thank all the nurses who participated in this study, without their participation this paper would not have been possible.

\section{Conflicts of Interest}

No conflict of interest.

\section{References}

[1] Wang, X., Kunaviktikul, W. and Wichaikhum, O. (2013) Work Empowerment and Burnout among Registered Nurses in Two General Tertiary Hospitals. Journal of Clinical Nursing, 22, 2896-2903. https://doi.org/10.1111/jocn.12083

[2] Van Bogaert, P., et al. (2014) Nursing Unit Teams Matter: Impact of Unit-Level Nurse Practice Environment, Nurse Work Characteristics, and Burnout on Nurse Reported Job Outcomes, and Quality of Care, and Patient Adverse Events-A Cross-Sectional Survey. International Journal of Nursing Studies, 51, 1123-1134. https://doi.org/10.1016/j.ijnurstu.2013.12.009

[3] Wang, S., Liu, Y. and Wang, L. (2015) Nurse Burnout: Personal and Environmental Factors as Predictors. International Journal of Nursing Practice, 21, 78-86.

https://doi.org/10.1111/ijn.12216 
[4] Nowrouzi, B., et al. (2015) Occupational Stress Management and Burnout Interventions in Nursing and Their Implications for Healthy Work Environments: A Literature Review. Workplace Health \& Safety, 63, 308-315. https://doi.org/10.1177/2165079915576931

[5] Turton, D.W. (2007) Review of Burnout: The Cost of Caring. Mental Health, Religion \& Culture, 10, 75-88. https://doi.org/10.1080/13694670600593697

[6] Kernick, D.P. (2003) Introduction to Health Economics for the Medical Practitioner. Postgraduate Medical Journal, 79, 147-150. https://doi.org/10.1136/pmj.79.929.147

[7] Morris, S., Devlin, N. and Parkin, D. (2012) Economic Analysis in Health Care. 2nd Edition, John Wiley \& Sons, Chichester.

[8] Yip, W. and Hafez, R. (2015) Improving Health System Efficiency. http://apps.who.int/iris/bitstream/10665/185989/1/WHO_HIS_HGF_SR_15.1_eng. pdf?ua $=1$

[9] Patrick, B.K. and Lavery, F.J. (2006) Burnout in Nursing. Australian Journal of Advanced Nursing, 24, 43-48.

[10] d'Ettorre, G. and Greco, M. (2015) Healthcare Work and Organizational Interventions to Prevent Work-Related Stress in Brindisi, Italy. Safety and Health at Work, 6, 35-38. https://doi.org/10.1016/j.shaw.2014.10.003

[11] Smollan, R.K. (2015) Causes of Stress before, during and after Organizational Change: A Qualitative Study. Journal of Organizational Change Management, 28, 301-314. https://doi.org/10.1108/JOCM-03-2014-0055

[12] Al-Turki, H.A., et al. (2010) Burnout Syndrome among Multinational Nurses Working in Saudi Arabia. Annals of African Medicine, 9, 226-229. https://doi.org/10.4103/1596-3519.70960

[13] Al-Turki, H.A. (2010) Saudi Arabian Nurses Are They Prone to Burnout Syndrome? Saudi Medical Journal, 31, 313-316.

[14] Jourdain, G. and Chênevert, D. (2010) Job Demands-Resources, Burnout and Intention to Leave the Nursing Profession: A Questionnaire Survey. International Journal of Nursing Studies, 47, 709-722. https://doi.org/10.1016/j.ijnurstu.2009.11.007

[15] Maslach, C. and Jackson, S.E. (1981) The Measurement of Experienced Burnout. Journal of Occupational Behavior, 2, 99-113. https://doi.org/10.1002/job.4030020205

[16] Hunsaker, S., Chen, H.-C., Maughan, D. and Heaston, S. (2015) Factors That Influence the Development of Compassion Fatigue, Burnout, and Compassion Satisfaction in Emergency Department Nurses. Journal of Nursing Scholarship, 47, 186-194. https://doi.org/10.1111/jnu.12122

[17] Toh, S., Ang, E. and Devi, M. (2012) Systematic Review on the Relationship between the Nursing Shortage and Job Satisfaction, Stress and Burnout Levels among Nurses in Oncology/Haematology Settings. International Journal of Evidence-Based Healthcare, 10, 126-141. https://doi.org/10.1111/j.1744-1609.2012.00271.x

[18] Adriaenssens, J., De Gucht, V. and Maes, S. (2015) Determinants and Prevalence of Burnout in Emergency Nurses: A Systematic Review of 25 Years of Research. International Journal of Nursing Studies, 52, 649-661. https://doi.org/10.1016/j.ijnurstu.2014.11.004

[19] Almalki, M., Fitzgerald, G. and Clark, M. (2011) Health Care System in Saudi Arabia: An Overview. Eastern Mediterranean Health Journal, 17, 784-793. https://doi.org/10.26719/2011.17.10.784 
[20] Almalki, M., FitzGerald, G. and Clark, M. (2011) The Nursing Profession in Saudi Arabia: An Overview. International Nursing Review, 58, 304-311. https://doi.org/10.1111/j.1466-7657.2011.00890.x

[21] Poghosyan, L., Aiken, L. and Sloane, D. (2009) Factor Structure of the Maslach Burnout Inventory: An Analysis of Data from Large Scale Cross-Sectional Surveys of Nurses from Eight Countries. International Journal of Nursing Studies, 46, 894-902. https://doi.org/10.1016/j.ijnurstu.2009.03.004

[22] Maslach, C., Schaufeli, W. and Leiter, M. (2001) Job Burnout. Annual Review of Psychology, 52, 397-422. https://doi.org/10.1146/annurev.psych.52.1.397

[23] Sabbah, I., Sabbah, H., Sabbah, S., Akoum, H. and Droubi, N. (2012) Burnout among Lebanese nurses: Psychometric Properties of the Maslach Burnout Inventory-Human Services Survey (MBI-HSS). Health, 4, 644-652.

https://doi.org/10.4236/health.2012.49101

[24] Rikard, L., Alenius, L.S., Griffiths, P., Runesdotter, S. and Tishelman, C. (2015) Structural Characteristics of Hospitals and Nurse-Reported Care Quality, Work Environment, Burnout and Leaving Intentions. Journal of Nursing Management, 23, 263-274. https://doi.org/10.1111/jonm.12123

[25] Alharbi, J., et al. (2016) The Factors Influencing Burnout and Job Satisfaction among Critical Care Nurses: A Study of Saudi Critical Care Nurses. Journal of Nursing Management, 24, 708-717. https://doi.org/10.1111/jonm.12386

[26] Gray-Toft, P. and Anderson, J.G. (1981) The Nursing Stress Scale: Development of an Instrument. Journal of Behavioral Assessment, 3, 11-23.

https://doi.org/10.1007/BF01321348

[27] French, S.E., Lenton, R., Walters, V. and Eyles, J. (2000) An Empirical Evaluation of an Expanded Nursing Stress Scale. Journal of Nursing Measurement, 8, 161-178. https://doi.org/10.1891/1061-3749.8.2.161

[28] McGilton, K.S., McGillis Hall, L., Wodchis, W. and Petroz, U. (2007) Supervisory Support, Job Stress, and Job Satisfaction among Long-Term Care Nursing Staff. The Journal of Nursing Administration, 37, 366-372. https://doi.org/10.1097/01.NNA.0000285115.60689.4b

[29] Milutinović, D., Golubović, B., Brkić, N. and Prokeš, B. (2012) Professional Stress and Health among Critical Care Nurses in Serbia. Archives of Industrial Hygiene and Toxicology, 63, 171-180. https://doi.org/10.2478/10004-1254-63-2012-2140

[30] Saleh, A.M., Saleh, M.M. and Abu Ruz, M.E. (2013) The Impact of Stress on Job Satisfaction for Nurses in King Fahad Specialist Hospital-Dammam-KSA. Journal of American Science, 9, 371-377.

[31] Johansen, M.L. and Cadmus, E. (2016) Conflict Management Style, Supportive Work Environments and the Experience of Work Stress in Emergency Nurses. Journal of Nursing Management, 24, 211-218. https://doi.org/10.1111/jonm.12302

[32] Price, J. and Mueller, C. (1981) A Causal Model of Turnover for Nurses. Academy of Management Journal, 24, 543-565. https://doi.org/10.5465/255574

[33] Agho, A.O., Mueller, C.W. and Price, J.L. (1993) Determinants of Employee Job Satisfaction: An Empirical Test of a Causal Model. Human Relations, 46, 1007-1027. https://doi.org/10.1177/001872679304600806

[34] Steel, R.P. and Lounsbury, J.W. (2009) Turnover Process Models: Review and Synthesis of a Conceptual Literature. Human Resource Management Review, 19, 271-282. https://doi.org/10.1016/j.hrmr.2009.04.002

[35] Gill, B., Deagan, E. and McNett, M. (2010) Expectations, Perceptions, and Satisfac- 
tion of Graduate Nurses. Journal for Nurses in Staff Development, 26, E11-E17. https://doi.org/10.1097/NND.0b013e31819b5ef4

[36] Özpehlivan, M. and Acar, A.Z. (2015) Assessment of a Multidimensional Job Satisfaction Instrument. Procedia-Social and Behavioral Sciences, 210, 283-290. https://doi.org/10.1016/j.sbspro.2015.11.368

[37] Sabanciogullari, S. and Dogan, S. (2015) Relationship between Job Satisfaction, Professional Identity and Intention to Leave the Profession among Nurses in Turkey. Journal of Nursing Management, 23, 1076-1085. https://doi.org/10.1111/jonm.12256

[38] Cortese, C.G. (2012) Predictors of Critical Care Nurses' Intention to Leave the Unit, the Hospital, and the Nursing Profession. Open Journal of Nursing, 2, 311-326. https://doi.org/10.4236/ojn.2012.223046

[39] Kalof, L., Dan, A. and Dietz, TH. (2008) Essentials of Social Research. McGraw Hill/Open University Press, Maidenhead.

[40] The Saudi Net (2007) Saudi Labor \& Workmen Law. http://www.the-saudi.net/business-center/labor_law.htm

[41] Lamadah, M.S. and Sayed, Y.H. (2014) Challenges Facing Nursing Profession in Saudi Arabia. Journal of Biology, Agriculture and Healthcare, 4, 20-25.

[42] Al-Makhaita, M.H., Sabra, A.A. and Hafez, S.A. (2014) Predictors of Work-Related Stress among Nurses Working in Primary and Secondary Health Care Levels in Dammam, Eastern Saudi Arabia. Journal of Family \& Community Medicine, 21, 79-84. https://doi.org/10.4103/2230-8229.134762

[43] Laranjeira, C.A. (2011) The Effects of Perceived Stress and Ways of Coping in a Sample of Portuguese Health Workers. Journal of Clinical Nursing, 21, 1755-1762. https://doi.org/10.1111/j.1365-2702.2011.03948.x

[44] Xie, Z., Wang, A. and Chen, B. (2011) Nurse Burnout and Its Association with Occupational Stress in a Cross-Sectional Study in Shanghai. Journal of Advanced Nursing, 67, 1537-1546. https://doi.org/10.1111/j.1365-2648.2010.05576.x

[45] Atefi, N., Abdullah, K.L., Wong, L.P. and Mazlom, R. (2014) Factors Influencing Registered Nurses Perception of Their Overall Job Satisfaction: A Qualitative Study. International Nursing Review, 61, 352-360. https://doi.org/10.1111/inr.12112

[46] AL-Dossary, R., Vail, J. and Macfarlane, F. (2012) Job Satisfaction of Nurses in a Saudi Arabian University Teaching Hospital: A Cross-Sectional Study. International Nursing Review, 59, 424-430. https://doi.org/10.1111/j.1466-7657.2012.00978.x

[47] Kaddourah, B.T., Khalidi, A., Abu-Shaheen, A.K. and Al-Tannir, M.A. (2013) Factors Impacting Job Satisfaction among Nurses from a Tertiary Care Centre. Journal of Clinical Nursing, 22, 3153-3159. https://doi.org/10.1111/jocn.12261

[48] Karkar, A., Dammang, M.L. and Bouhaha, B.M. (2015) Stress and Burnout among Hemodialysis Nurses: A Single-Center, Prospective Survey Study. Saudi Journal of Kidney Diseases and Transplantation, 26, 12-18. https://doi.org/10.4103/1319-2442.148712

[49] Dasgupta, P. (2012) Effect of Role Ambiguity, Conflict and Overload in Private Hospitals' Nurses' Burnout and Mediation Through Self Efficacy. Journal of Health Management, 14, 513-534. https://doi.org/10.1177/0972063412468980

[50] Kozak, A., Kersten, M., Schillmöller, Z. and Nienhaus, A. (2013) Psychosocial Work-Related Predictors and Consequences of Personal Burnout among Staff Working with People with Intellectual Disabilities. Research in Developmental Disabilities, 34, 102-115. https://doi.org/10.1016/j.ridd.2012. 07.021 
[51] Hamaideh, S.H. (2011) Burnout, Social Support, and Job Satisfaction among Jordanian Mental Health Nurses. Issues in Mental Health Nursing, 32, 234-242. https://doi.org/10.3109/01612840.2010.546494

[52] Vargas, C., Cañadas, G.A., Aguayo, R., Fernández, R. and de la Fuente, E.I. (2014) Which Occupational Risk Factors Are Associated with Burnout in Nursing? A Meta-Analytic Study. International Journal of Clinical Health \& Psychology, 14, 28-38. https://doi.org/10.1016/S1697-2600(14)70034-1

[53] Takase, M. (2010) A Concept Analysis of Turnover Intention: Implications for Nursing Management. Collegian, 17, 3-12. https://doi.org/10.1016/j.colegn.2009.05.001

[54] Jamal, M. (2010) Burnout among Canadian, Chinese, Malaysian and Pakistani Employees: An Empirical Examination. International Management Review, 6, 31-41. 